\title{
Knowledge of Fathers' Support during Labor: From Arabic Fathers' Perspective
}

\author{
Hala A. Bawadi* \\ Maternal and Child Health Nursing Department, Faculty of Nursing, The University of Jordan, Amman, Jordan \\ Email: h.bawadi@ju.edu.jo
}

Received 11 October 2015; accepted 15 November 2015; published 18 November 2015

Copyright (C) 2015 by author and Scientific Research Publishing Inc.

This work is licensed under the Creative Commons Attribution International License (CC BY). http://creativecommons.org/licenses/by/4.0/

c) (i) Open Access

\begin{abstract}
Aim: The aim of this study was to assess the kind of labor support Arab fathers could offer their wives. Design and Method: An interpretative phenomenological approach was used to reveal the meaning attributed by Arabic fathers regarding their support during labor. Individual, semistructured interviews were conducted with 19 Arabic fathers. The analysis was done by using Smith's model of interpretive phenomenological analysis (IPA) together with software package NVivo7. Findings: The analysis of the interviews illustrated the types of labor support offered by Arabic fathers to their wives. Three main themes emerged from the data: physical support, emotional support, and spiritual support. Conclusion: The support offered by Arabic fathers was in the minimal degree and missing practical support. Socio cultural issues and health policies prevented fathers from playing an active role during labor. There is a need to develop policies and regulations that enhance more inclusion of fathers in maternity services including the labor room.
\end{abstract}

\section{Keywords}

\section{Arab fathers, Labor, Support}

\section{Introduction}

In the past few decades, healthcare providers have had an increasing interest in involving males in reproductive health. This emergent concern emphasized on men's behavior, information and reacting methods towards their own and women's reproductive health. Parallel to this interest, there is also rising in academic research of how men develop their male identity through their life experience, and how they interact and shape relationships with others including their relations with their wives and children [1]. In this context, some researches explored fathering phenomena from the perspectives of men, such as what fathering means, at what point they prepare themselves for fathering, and the factors affected the fathering process. These studies based on men's parenting

\footnotetext{
*The author is an Assistant Professor.
} 
became a multidisciplinary science of specialized knowledge. The results in searching how males live their lives, lead to focus on men's contribution to family life, including the parenting process.

While studying parenting process, some researchers investigated fathers' involvement during the maternity period. The conclusions for these researches were mirrored the positive aspects of fathers' involvement as well as the challenging issues of male involvement in maternity care for his female partner. In 1960s-1970s health services in Western countries encouraged men to participate in maternity care for their partner and taking a more active role [1]. A study conducted by Draper (1997) showed that in the mid-1990s, 95\% of expectant fathers in England were attendant at the birth of their babies [2]. The significance of early engaging the fathers on pregnancy, labor, and postpartum care has been investigated in many nursing and midwifery literatures [1] [3]-[5]. It is found that father support during labor promotes mother well-being in the future, and enhances his attachment to the upcoming baby, as a result, the fathers who were given the chance to participate in the labor process reported more satisfaction in their experiences. Moreover, it was proven that close contact between the couple will assist in better child development [6].

However, fathers are not always encouraged to engage during labor, some cultural norms and practices have shown to stop father involvement during labor [4]. The fathers' perspectives about their role during labor fluctuate internationally, from cultural prohibition of father presence during labor, to full support physically and emotionally to laboring woman [5].

Labor support means the availability of an affectionate one who offers needed knowledge, counseling, realistic assistance, and other relaxing methods that help the woman cope during labor and delivery. Women in labor are in immense need of companionship from a compassionate and helpful person. Iliadou (2012) argued that the key component of emotional support of intrapartum care includes encouragement, protection, and contentment [3]. In addition to that, the companion must give full attention and physical presence throughout the labor period.

Despite the benefits of father support during labor, the role of Arabic fathers in labor remains unclear. The patriarchal family structures in Arabic societies limit the father role and responsibility during labor. This perception is connected strongly to the idea that childbirth is a feminine issue [7]. The masculine mindset is relatively dominated in Arabic countries. This is also clear by the norm that fathers are the decision makers and are responsible for financial support of the family, while the mothers' roles are restricted to childbearing and providing care to children and the elderly [8]. To date, a few studies have been conducted to investigate the role of Arabic father in maternal health in general and during labor in particular. Bringing to light that the degree and type of contribution Arabic fathers could offer to their wives during their maternity period would be important for program planning and policy makers to deliver high quality maternal health care services. Therefore, the aim of this study was to assess the kind of support Arabic fathers could offer their wives during labor.

\section{Method}

A phenomenological approach was used as a framework to study the life experience of Arabic fathers during the labor of their wives and how they support them. The philosophy of phenomenology depends on revealing the heading meaning of a world life event from the perceptive of people who have gone through this event, and generate descriptive data that enhances a deeper understanding of life experience [9].

The study was conducted in two Arabic countries, Saudi Arabia and Jordan. Ethical approval was secured from the Research Ethics Committee at the nursing faculty in the Applied Science University in Jordan. Purposive sampling of nineteen men was used; nine Saudi Arabian men and ten Jordanian men were enrolled in the study. The sample included Arabic fathers living in either country whose wives had experienced pregnancy and childbirth within the previous 24 months, were stayed with their wives when she going through labor, and were willing to participate in the study. The snowball sampling technique was used to access the potential participants. After meeting the inclusion criteria, an information sheet was sent to expectant participants and answered any queries, and then the date of the interview was arranged. Individual semi-structured interviews were conducted in the participants' homes or in a coffee shop, according to their preferences. During the interviews, we used interview guides that were designed by the researchers and asked participants for permission to tape record the interviews. Interviews with fathers lasted between 55 and 80 minutes, during the period from September 2012 to April 2014. Interviews were transcribed, translated into English, and analyzed using the principles of Interpretative Phenomenological Analysis (IPA) [10], added by using the NVivo 7 program. The analysis started with a practice of self-reflection as a foundation stage of research analysis. After transcription of all interviews, the 
idea that represented each paragraph was coded with a keyword, and then the remaining interviews were coded in the same way. After that, the key words were clustered as parent nodes and tree nodes, all that work was done by using the NVivo 7 program. Then the analysis was completed by handwriting that each tree node was documented by a core idea that explains the meaning of that tree node. Subsequently, the theme was concluded from each idea. Then the final list of themes was constructed and represented by quotes from the participants' interviews.

\section{Findings}

Our participants were 19 fathers: 10 from Jordan and 9 from Saudi Arabia. The fathers' ages varied between 22 to 41 years. And their educational degree varied from who had completed compulsory school to others with an academic degree in various subjects. All the fathers had accompanied their wives during pregnancy and labor.

Labor is perceived as an intense physical and emotional period. The woman will be comfortable if she is encouraged and reassured that she is progressing well. Also, she is in need of a comforting touch and assistance in back massage and position changing, among a few other things. The most supporting person at this time is the father, who could guide the woman during this tough period. It was confirmed that husband involvement during labor can result in positive labor ending for the mother and newborn, as well as a valid conjugal relationship. However, this is not always the case with all laboring woman. The degree and type of support varies greatly from one society to another according to their cultural norms and practices. This study explored how Arabic fathers supported their wives during labor. The participants mentioned that the time they spend with their wives is very short; they only stay with them from when they start feeling contractions until they are escorted to the labor room, as hospital policy prevents husbands from accompany their woman inside labor room, so the woman doesn't receive continuous support from her husband. The fathers narrated in a vivid picture how they deal with their wives during this time, and what kind of treatment they offer. The findings of this study revealed a major theme that comes into sight from the narratives of the participants "Kinds of Arabic fathers' support offered during labor”, which contained three sub-themes: physical, emotional, and spiritual support.

\subsection{Physical Support}

All the fathers asserted that labor is an exciting time; the couple will wonder if it is true labor or a false start, if the woman really is in labor, the feelings will switch to panic, dread and nervousness. Therefore, the laboring woman is in need of continuous support to overpass this critical period. While the fathers in this study had various points of view about how the one could support his woman during labor, all of them agreed that the woman in need of support when she starts suffering from labor pain. This top to bottom desire was restricted by barriers and kept their support at minimum level. This theme talks about physical support offered by fathers while wives were suffering from labor pain. The participants asserted that the shortness of time until they escorted them to the hospital deprived them from giving their full support, they believed their support was not enough and efficient. The participants said that they firstly supported the woman by trying to let her feel comfortable by reminding her to take deep breaths, assisting her in showering, helping her wear clothes, checking the prepared bag for hospital, and preparing hot drinks and encouraging her to eat dates. They stated they offered these simple services until they decide it is a suitable time to go to the hospital.

The contractions started with my wife at about 1:30 am, but she refused to go to the hospital right away, she wanted to stay home until the contractions came every 5 - 7 minutes. During that time, I helped her sit comfortably on the sofa and put one pillow under her right side, she felt comfort in that position. I also prepared herbal tea for her, which would decrease her cramps (38 years old, Jordan).

When she started feeling labor pain, I helped her change her clothes, and brought the items she requested to take with her to the hospital. Then we went to the hospital, I didn't know what to do in this condition, it was safer for her to be in the hospital with professionals taking care of her (29 years old, Saudi Arabia).

I stayed with my wife for around two hours before we went to the hospital. I tried relieving her from her pain. I didn't know if my help was useful, but I wanted her to feel that I am with her. I assisted her to walk around the houses and reminded her to breathe slowly when feeling pain. When she seemed sweaty I would wipe her face (35 years old, Saudi Arabia).

However, the fathers in this study underestimated their support, and confessed they were not the right person to could chaperone the woman during labor. They asserted they were not well prepared for this role, and many 
cultural factors prevent them being involved during this critical period. They accorded that woman to woman support is more helpful for laboring women. The fathers in this study delegated their job of staying with their wives during labor to a female member of their families. They found that transporting their mother or mother in law and escorting them to the hospital is considered as support to their wives; a female available with a laboring wife is more relatable for the helping female, as she will be more oriented to all female issues, and will have had previous experience with pregnancy.

When the cramps started with my wife, and she was certain they came regularly, she immediately asked for her mother, she wanted her to be around. So I phoned my mother-in-law to be ready when we come to pick her upon our way to the hospital. I think my wife felt securer with her mother (33 years old, Jordan).

My mother and sister requested permission from me to accompany my wife when she went into labor, and my wife was happy with that, so I took them to the hospital after the doctor examined my wife. I then also phoned her family to inform them that she was in labor, and her mother came (40 years old, Jordan).

\subsection{Emotional Support}

The fathers emphasized the importance of providing reassurance, encouragement, and sympathizing with the wife. The participants admitted they knew that labor pain is too much and is unbearable. So, the woman will be vulnerable in feeling fatigue and weakness. As the fathers were not educated before delivery about ways to decrease women's' labor pain, they discovered that there were simple measurements they could offer that meant a lot to the wife, which also boosted her stamina and will. The fathers were extremely enthusiastic and emboldening to keep the woman feeling secure and encourage her to be patient and strong.

The fathers expressed their feeling that it was hard for them to see their wives in such pain as they went through labor, but they also mentioned that the woman will be more confident and believing of her capability if the father can strengthen her. The participants agreed that reassurance will empower the woman and decrease her despair. They stated that they always kept eye contact with their wives when reassuring them about their condition, and they never showed their fear or panic to them, in hopes of keeping the wife in the best mentality possible. Moreover, they keep assuring her that this is a normal process and that she could power through it.

When she was in the labor room, I kept talking with her on the phone, telling her that I spoke to the doctor, and she informed me you are progressing well (26 years old, Saudi Arabia).

I know I have to be strong during this time because it will reflect on my wife. She was so scared and cried excessively. I told her that all mothers in my family and her family went through this phase, and now they are enjoying it with their kids. You will be alright, now we will go to the hospital and you will be in trusted hands and great care. With God's will, tomorrow you will be the mother of an angel baby (21 years old, Saudi Arabia).

The labor is perceived as an overwhelming experience, and the emotions were swinging between excitement, anxiety and anticipation. The laboring woman should comprehend that she is not alone, and her partner appreciates the pains she goes through. To the cause of enduring such great pain, the woman will be fragile. She will be in need of a tender person who will offer kindness and compassion. The fathers in the study explained how they showed sympathy to their wives. They were persistently asking their wives what they can do to soothe the pain.

When the contractions started, and I saw my wife anxious and worried about giving birth, I kept hold of her hand, it was immensely comforting for her. I was scared like her, but tried not to show it (24 years old, Saudi Arabia).

I was regularly comforting her until we arrived at the hospital. I asked about her about her thoughts and concerns, showing her care and compassion throughout the trip, trying to do the most I could for her (32 years old, Saudi Arabia).

The birth of the baby is from the most influential and pleasing moments in the couple's life. Also, this experience marks the end of long moments of restlessness. The couple needs to be a unit to overpass this tough period and rule out any frightening thoughts. The woman throughout labor will be anxious and frustrated; she will look to her husband for strength and encouragement. Encouragement is the key of emotional labor support. Many of the participants found it was hard to watch their wife in pain when you couldn't stop it. But they had a major role in empowering the woman during this experience. The participants kept telling their wives that they were doing really well in coping with all this stress, which gives woman confidence to continue. The following quotes will explain how fathers encouraged their wives.

When the cramps become more intense, and I saw from her facial expressions how much she was suffering, I 
wanted to do everything to relieve her from her pain, but the problem was that I couldn't. This is a normal process and will take time. So I told her she would get past it, this pain is the motherhood tax. After a few hours you will see the baby and feel he deserved this agony (27 years old, Jordan).

In the short time I stayed with my wife, I was telling her you are the hero of this day; you will feel pain for short while, but then when you hold our baby you will forget the misery (31 years old, Jordan).

\subsection{Spiritual Support}

The most excruciating event in women's life is labor; it will generate pain and discomfort both mentally and psychically. During this intense period the woman's distress will increase. It will not be easy to endure all these recurrent spasms, and negative and positive emotions will be brought to the surface. These strong emotions will be differing from one woman to another, and many factors will play a role in it. As all the participants in this study were Muslims, they narrated how spirituality helps in evoking positive feelings of serenity and security, and reducing negative feelings like anxiety that arouse from persistent fear of labor. In the context of Islam, labor time is viewed in a religious light, and the woman will be born again after suffering labor pain. Prophet Mohammed - peace be upon him—said "if we serve our mothers for all our lives, it will not equal the pain of one contraction of when she delivered us". The woman will be rewarded for her suffering during the birth of the baby; Allah promised the laboring woman that her sins will be erased after the delivery. This is one of cause why Islam granted a fertile woman a superior status. The informants describe how their religious practices provided the women with the sense of calmness and peacefulness.

The fathers expressed a feeling of satisfaction in how they supported the woman spiritually. They recalled how they would read verses from the holy book "Quran” and remind the woman to read Quran. Muslims believed that labor will not finish safely without the help of Allah, so they need to get closer to Allah by reading the Quran; this will relax the woman and inspire her to tolerate labor pain.

When her labor pain began and the cramps became more frequent, I played a Quran tape, its sound echoed throughout the house. The sound of the Quran was very soothing to both my wife and I (41 years old, Saudi Arabia).

I would put my hand on her forehead, reading some verses of Quran, it was comforting her. I also kept reminding her to read what she had memorized by heart (35 years old, Jordan).

The status of mothers is high in Islam. Allah ordered Muslims to respect the womb that bore them. Moreover, Prophet Mohammed -peace be upon him- said that "Paradise lies at the feet (serving the needs) of one's mother". One of the most important things Muslims must keep in mind when dealing with their mother is the pain she suffered from when she delivered them. Allah rewards the mother for that by cleansing all her sins after the birth of the baby. This is one of the facts that Muslims believed in and it empowered them deeply during labor. The following quotes explain that:

I kept her enduring the pain by telling her: it is a privilege for mothers that Allah distinguishes them from the fathers. Our prophet in this regard said that "one owes their mother three times more love and obedience than that owed to one's father" (28 years old, Saudi Arabia).

I was telling her that this intense pain is the price of mothering, and with Allah with her, she will be rewarded for the suffering she went through (24 years old, Jordan).

Labor is considered a highly agonizing and taxing event. As a result Muslims turn to God for assistance and comfort. They intensify their praying during labor time as the woman will be in Allah's hands and under his care. They thoroughly believe that with the help of Allah, the labor will turn out well and Allah will grant the mother and her baby a healthy condition and a healthy body. Their prayers emphasized on protection from complications and difficulties, and the safety of the mother and newborn.

I kept asking Allah to relieve her from her pain and decrease her suffering. I also prayed for a healthy baby (29 years old, Jordan).

I persevered praying for her and reminded her to pray. I was confident of a response to my prayers. I asked Allah to give my wife strength to overcome this phase, and to grant her and our baby good health (28 years old, Jordan).

\section{Discussion}

One of the most significant experiences in the life of man is to be a father. This experience is extremely emo- 
tional and loaded with diversified feelings such as apprehension, suspense, and enjoyment. All these emotions are controlled and moved toward a positive side according to the degree of father's engagement in labor and the support he could offer to the laboring woman. How do the fathers perceive their support during labor and what kind of help do they offer their wives during labor? These two queries should be answered prior enhancing fathers' participation in labor. Until now, few researchers have investigated the labor experience for Arabic fathers and what kind of support they share with their wives. While in developed countries the paternal involvement during labor received greater attention from researchers, in Arabic countries the situation differs and the effort a father could offer is underestimated. Therefore, the focus of this research was to explore how Arabic fathers supported their wives during labor, hoping the results help healthcare providers and stakeholders in maternity services in setting programs and policies that give fathers further space to support their wives in a more meaningful way during labor.

The findings show that the labor experience is perceived by Arabic fathers as a tough period mutually for the mother and father; while the mother suffers physically and emotionally during this period, the father is exposed to excitement, stress and anxiety. These results were in-line with Premberg et al. [5] results. Both studies revealed that the couple is one unit and they share the childbirth experience, but the understanding of sharing and how to apply it differs between participants in our current study and participants in the Premberg study. In the current study, fathers had a lower role because of the restricted time they spend with wives and a lack of preparation to handle labor. In comparison to the fathers in the Premberg study, the maternity policy encouraged fathers to stay with their wife and attend the delivery, as there was no cultural issue preventing the father from taking an active role. They supported the wife in a more profound way, the fathers were will prepared to take a main role during labor, doing jobs such as noting the frequency of contractions, massaging the wife's back, and changing her position while seated. The support of fathers in developed countries was obviously noted during labor, the main reason for that was because of antenatal education classes. Pestvenidze and Bohrer argued that antenatal educational classes played a leading part in enhancing fathers' involvement in labor, and it was proven to be effective in reducing the stress of laboring women by preparing the couple psychologically and emotionally for labor [11]. A phenomenological study conducted in Syria concluded that Arabic fathers' involvement during labor was restricted to psychological support only and missed practical support that was in turn given by health care providers. Abushaikha and Massah, explained the barrier that hampered Arabic fathers from playing an active role during their wives' delivery. They summarized it in absence of preparation by expectant fathers for the labor experience offered by antenatal classes, unsupportive maternity policies and health teams that excluded them from the labor room, and socio cultural restrictions that prohibited fathers' availability in the labor room and attending the delivery of the baby [7] [12]. These results showed familiarity to our results as fathers considered childbirth a female issue and thought they could not be useful to a woman during this period because they lack the knowledge and practices of what to do. Consequently, they were delegating all these responsibilities to other female members in the family.

As previously mentioned, the fathers perceive labor as a shared experience. They were sharing the mother's mental pain so they supported her emotionally. The participants identified their role during labor as providing encouragement and reassurance and sympathizing with their wife. They found these simple measurements were fairly comforting for the wife decreased her anxiety level. According to Plant in et al., fathers who psychologically support their wives during delivery can reduce the anxiety, pain, and exhaustion for the woman. In addition, woman reported positive perception of their childbirth experience [1].

In this study all participants were Muslim and perceived labor in a greatly religious light. This was one of the main themes discussed in the study as fathers emphasized praying for the mother to safeguard her and the baby from all hardships. This is directly related to the strong belief of Muslims that prying to Allah during tough times will protect them from all hazards. This theme was congruent with Abushaikha and Massah [12]. As praying was essentially offered during labor as Muslims view praying as a religious daily obligation, and pray intensively during stressful times.

The involvement of fathers is a major issue during labor. The father must be physically available during all stages of labor, not only while the woman goes through contractions at home. This study presents initial information on how Arabic fathers support their wives during labor. Findings of this study may raise the policy makers of maternity services' interests to set programs that encourage the handiness of fathers during labor. Fathers are in immense need for educational classes on how to handle labor. Maternity staff, especially nurses, should play an active role in engaging fathers in maternity care and labor care. On the national level, regulations em- 
phasizing a family-centered approach in maternity services should be placed

\section{Limitations of the Study}

The study has effectively addressed the type of support offered by Arabic fathers to their wives during birth, however it still has some limitations. One of the limitations was the small sample size, which may limit the generalisability of the findings, which was not the aim of the study. Another limitation was that we explored the kind of support offered from the perspective of father only, maybe if we conduct interviews with the couple as a joint group that may give us a more detailed experience.

\section{References}

[1] Plantin, L., Olukoya, A. and Ny, P. (2011) Positive Health Outcomes of Fathers' Involvement in Pregnancy and Childbirth Paternal Support: A Scope Study Literature Review. Fathering, 9, 87-102. http://dx.doi.org/10.3149/fth.0901.87

[2] Draper, J. (1997) Whose Welfare in the Labour Room? A Discussion of the Increasing Trend of Fathers' Birth Attendance. Midwifery, 13, 132-138. http://dx.doi.org/10.1016/S0266-6138(97)90003-6

[3] Iliadou, M. (2012) Supporting Women in Labour. Health Science Journal, 6, 385-391.

[4] Story, W., Burgard, S., Lori, J., Fahmida, T., Ali, N. and Hoque, D.M. (2012) Husbands’ Involvement in Delivery Care Utilization in Rural Bangladesh: A Qualitative Study. BMC Pregnancy and Childbirth, 12, 28. http://dx.doi.org/10.1186/1471-2393-12-28

[5] Premberg, Å., Carlsson, G., Hellström, A.L. and Berg, M. (2011) First-Time Fathers’ Experiences of ChildbirthAphenomenological Study. Midwifery, 27, 848-853. http://dx.doi.org/10.1016/j.midw.2010.09.002

[6] Wong, S., Mangelsdorf, S., Brown, G., Neff, C. and Schoppe-Sullivan, S. (2009) Parental Beliefs, Infant Temperament, and Marital Quality: Associations with Infant-Mother and Infant-Father Attachment. Journal of Family Psychology, 23, 828-838. http://dx.doi.org/10.1037/a0016491

[7] Abushaikha, L. and Massah, R. (2013) Perceptions of Barriers to Paternal Presence of Contribution during Childbirth: An Exploratory Study from Syria. Birth, 40, 61-66. http://dx.doi.org/10.1111/birt.12030

[8] Endrawes, G., O’Brien, L. and Wilkes, L. (2007) Egyptian Families Caring for A Relative with Mental Illness: A Hermeneutic Study: Feature Article. International Journal of Mental Health Nursing, 16, 431-440. http://dx.doi.org/10.1111/j.1447-0349.2007.00498.x

[9] Dahlberg, K., Dahlberg, H. and Nyström, M. (2008) Reflective Lifeworld Research. 2nd Edition, Studentlitteratur, Lund.

[10] Smith, J., Flowers, P. and Larkin, M. (2009) Interpretative Phenomenological Analysis: Theory, Method and Research. Sage, Newcastle Upon Tyne.

[11] Pestvenidze, E. and Bohrer, M. (2007) Finally, Daddies in the Delivery Room: Parents’ Education in Georgia. Global Public Health, 2, 169-183. http://dx.doi.org/10.1080/17441690601054330

[12] Abushaikha, L. and Massah, R. (2012) The Roles of the Father during Childbirth: The Lived Experiences of Arab Syrian Parents. Health Care for Women International, 33, 168-181. http://dx.doi.org/10.1080/07399332.2011.610534 